\title{
To Evaluate The Effectiveness of Deep Breathing Exercises on Menopausal Symptoms Among Menopausal Mothers In Selected Community Area, Mangaluru.
}

\author{
Amitha Mohan ${ }^{1}$, Mrs. Sandhya D. Almedia ${ }^{2}$ \\ ${ }^{1}$ Msc.Nursing, Laxmi Memmorial college of Nursing (Obstetrical and gynaecological Nursing)Mangalore, \\ ${ }^{2}$ Laxmi college of Nursing, Upper Bendoor, Mangalore, India-575002.
}

\begin{abstract}
:
An Interventional study was conducted to identify the effect of deep breathing exercises on menopausal symptoms among menopausal mothers in community area, Mangalore. Quasi Experimental time series Design was adopted for the present study. A purposive sample of 60 mothers were selected and assigned randomly to Experimental Group and Control Group. The base line data was collected from the mothers and menopausal symptoms was assessed by using Menopausal Rating Scale. Deep breathing exercises was taught to the mother who belongs to Experimental Group .The menopausal rating scale was assessed for both the control group and Experimental Group. The result revealed that there is a significant reduction in menopausal symptoms in menopausal mothers after performing Deep breathing exercises in the Experimental Group.
\end{abstract}

Key Words: Deep breathing Exercises, Menopausal Mothers, Menopausal symptom scores,Effect.

\section{Introduction:}

In current society women play an important role in the family "Health is Wealth" if there is any alteration in the health of Women the house hold routines get altered. Women are the vital set up and heart of the family. When women are tired, family function would be altered. Women are facing lot more problems through their life. One of most common problem they are facing during menopause is hormonal changes during their middle adulthood

Menopause is the stage when the menstrual period permanently stops and is a part of every woman's life. This stage usually occurs between ages of 40 and 60 years, and is associated with hormonal, physical and psychological changes. These changes can occur gradually or abruptly. It can start as early as the age of 30 years or not until as late as 60 years. It can also occur when ovaries are removed or have stopped functioning. The mean age of onset of the menopausal transition is 47.5 years and commonly lasts approximately 4 to 5 years

Menopausal mothers in the community area has limited knowledge about deep breathing exercise Menopausal mothers shows various menopausal symptoms like hot flushes, weakness, urinary incontinence since there is a lack of knowledge regarding deep breathing exercise in the community area The investigator was interested to evaluate the effectiveness of deep breathing exercise on menopausal symptoms among menopausal mothers. The study would help the menopausal mother in relieving the menopausal symptoms experienced by the mother during menopause.

\section{Statement of The Problem:}

Effectiveness of Deep Breathing Exercises On Menopausal Symptoms Among Menopausal Mothers In Selected Community Area, Mangaluru.

Objectives: 
1. To determine the severity of menopausal symptoms among menopausal women in experimental group and control group.

2. To evaluate the effectiveness of deep breathing exercise on menopausal symptoms among menopausal women in experimental group.

3. To find the post-test of menopausal symptoms score among menopausal women in experimental group and control group.

4. To find the association of menopausal symptoms score among experimental group and control group with selected demographic variables.

\section{Hypotheses:}

The hypothesis are tested at 0.05 level of significance.

$\mathrm{H}_{1}$ : There is a significant difference in the menopausal symptoms scores of experimental group and the control group.

$\mathrm{H}_{2}$ : There is a significant association of menopausal symptoms scores with selected demographic variables.

\section{Materials and Methods:}

Quasi Experimental time series design was adopted to carry out the study.Baseline proforma was collected and pre-test was done by assessing the level of menopausal symptoms using Menopausal Rating Scale. Menopausal women with moderate to severe symptoms was taken for the study.Deep breathing exercise was demonstrated to the menopausal women (4-6) members in the Anganavadi in the morning for 10-15 minutes. Menopausal women was asked to practice deep breathing exercise in the evening for 10-15 minutes check list diary was maintained to record it .Observed the deep breathing exercise of menopausal women every day morning for 10-15 minutes for 15 days. After finishing the experimental group control group was taken for assessment and no intervention was given.

\section{Findings:}

Table 1: Unpaired ' $t$ ' test showing difference between the pre-test menopausal symptoms score with the post-test menopausal symptoms in the control and experimental group

\begin{tabular}{|c|c|c|c|c|c|c|}
\hline Group & & $\begin{array}{l}\text { Mean } \\
\text { Score }\end{array}$ & SD & $\begin{array}{c}\text { Mean } \\
\text { diff. }\end{array}$ & $\begin{array}{c}\mathbf{t} \\
\text { value }\end{array}$ & $\begin{array}{c}\mathbf{P} \\
\text { value }\end{array}$ \\
\hline Experimental group & \multirow[t]{2}{*}{ Pre-test } & 19.30 & 2.70 & \multirow[t]{2}{*}{1.60} & \multirow[t]{2}{*}{1.718} & \multirow[t]{2}{*}{0.023} \\
\hline Control group & & 17.70 & 2.75 & & & \\
\hline Experimental group & \multirow[t]{2}{*}{ Post-test 1} & 11.70 & 2.00 & \multirow[t]{2}{*}{6.43} & \multirow[t]{2}{*}{1.92} & \multirow[t]{2}{*}{0.031} \\
\hline Control group & & 18.13 & 2.72 & & & \\
\hline Experimental group & \multirow[t]{2}{*}{ Post-test 2} & 5.63 & 1.35 & \multirow[t]{2}{*}{12.87} & \multirow[t]{2}{*}{1.77} & \multirow[t]{2}{*}{0.021} \\
\hline Control group & & 18.50 & 2.64 & & & \\
\hline
\end{tabular}

$\mathrm{p}<0.05$; significant

Data in Table 1 showed that the mean pre-test scores of the experimental group is (19.30) is higher when compared with the mean post-test score of menopausal symptoms post-test $1=11.70$ and post-test $2=5.63$ of experimental group. Where $\mathrm{P}=0.023,0.031,0.021$, respectively, based on unpaired test analysis if $\mathrm{P}<0.05$ is significant. In control group there is significant increase in the post-test menopausal symptoms scores. 
Thus $\mathrm{H}_{0}$ was rejected and the research hypothesis was accepted i.e, after performing deep breathing exercise the menopausal symptoms scores of menopausal women were improved .

Table 2: Frequency and percentage distribution of subjects in experimental group and control group according to changes in the symptoms of menopausal mothers after deep breathing exercise

\begin{tabular}{|l|c|c|c|c|c|c|}
\hline \multirow{2}{*}{ Group } & \multicolumn{2}{|c|}{ Pre-test - 1 } & \multicolumn{2}{c|}{ Post-test 1 } & \multicolumn{2}{c|}{ Post-test 2 } \\
\cline { 2 - 7 } & f & \% & f & \% & F & \% \\
\hline Experimental group & & & & & & \\
\hline Mild & 0 & 0 & 10 & 33 & 30 & 100 \\
\hline Moderate & 19 & 63 & 20 & 77 & - & - \\
\hline Severe & 11 & 37 & 0 & 0 & - & - \\
\hline Control Group & & & & & & \\
\hline Mild & 0 & 0 & 0 & 0 & 0 & 0 \\
\hline Moderate & 25 & 83 & 24 & 80 & 23 & 77 \\
\hline Severe & 5 & 17 & 6 & 20 & 7 & 23 \\
\hline
\end{tabular}

The data presented in Table 2 showed that in the experimental group in the pre-test (63\%) had moderate symptoms whereas $37 \%$ of subjects had severe symptoms. In post-test $1,33 \%$ of subjects where having mild symptoms whereas $77 \%$ of subjects were having moderate symptoms. In post-test 2 all subjects, i.e., $100 \%$ where having mild symptoms. The result is relatively lower than in pre-test 1 . In control group Pre-test $1,83 \%$ of subjects were having moderate symptoms and $17 \%$ were having severe symptoms. In post-test $1,80 \%$ have moderate symptoms and in post-test $2,77 \%$ have moderate symptoms. In pre-test 1 , $17 \%$ have severe menopausal symptoms and $20 \%$ have severe menopausal symptoms in post-test $1.23 \%$ have severe menopausal symptoms in post-test 2 . There is increase in score of menopausal symptoms in control group.

\section{Discussion:}

With regards to the menopausal symptoms of $(30+30)$ mothers were randomly assigned to experimental and control group. Menopausal symptoms scores were assessed before and after administration of deep breathing exercises using menopausal rating scale. Paired $\mathrm{T}$ test, fishers exact probability test was used to prove the significance of this therapy. On comparing Table 1 and Table 2 the findings has resulted that there is a reduction in menopausal symptom scores among menopausal mothers during menopause. Hence deep breathing exercise can be adopted s an alternative medicines for conventional pharmacological treatments.

\section{Conclusion:}

Menopause is the stage when the menstrual period permanently stops and is a part of every woman's life. The study has provided the investigator with deep insight into the relief of menopausal symptoms scores of menopausal mothers and their significance of non pharmacological interventions in relieving the menopausal symptoms scores by providing deep breathing exercises as interventions.

References:

[1] Freeman EW, Sammel MD, Lin H, et al. Duration of menopausal hot flushes and associated risk factors. Obstet Gynecol 2011 May;117(5):1095-104. 
[2] Gold EB, Block G, Crawford S. Lifestyle and demographic factors in relation to vasomotor symptoms: baseline results from the Study of Women's Health Across the Nation. Am J Epidemiol 2004 Jun 15;159(12):1189-99.

[3] Slaven L, Lee C. Mood and symptom reporting among middle-aged women: The relationship between menopausal status, hormone replacement therapy, and exercise participation. Health Psychology 1997 May;16(3):203.

[4] Ricci SS, Kyle T. Maternity and paediatric nursing. Philadelphia: Lippincott Williams and Wilkins; 2009

[5] Obermeyer CM. Menopause across cultures: a review of the evidence. Menopause 2000;7(3):18492. 